\title{
TENDÊNCIA DO LOCUS DE CONTROLE DE PESSOAS DIABÉTICAS**
}

\author{
Maria Lúcia Zanetti** \\ Isabel Amélia Costa Mendes***
}

ZANETTI, M. L.; MENDES, I. A. C. Tendència do locus de controle de pessoas diabéticas.

Rev. Esc. Enf. USP., v. 27, n. 2, p. 246-62, ago. 1993.

A tendência do locus de controle de pessoas diabéticas é a temática abordada no contexto do papel do enfermeiro enquanto educador. O trabalho teve como objetivos testar a fidedignidade do Instrumento de Medida de Locus de Controle à Sauide. IMLCS, confrontar a distribuiçào das respostas aos diferentes itens do IMLCS para uma populaçào de pacientes diabéticos, e verificar a predominância do locus de controle à saúde nos sujeitos estudados. Os dados obtidos através da aplicaçào do referido instrumento em pacientes diabéticos permitiram-nos concluir que houve uma predominância de sujeitos com o locus do controle externo, que os diferentes itens foram respondidos de maneira favorável pelos sujeitos e que a escala está validada para a populaçáo de pacientes diabéticos. Acreditamos que os resultados obtidos apontam para a necessidade de se repensar o papel do enfermeiro frente às práticas educativas com pacientes diabéticos.

Unitermo: locus de controle, diabetes

\section{INTRODUÇÃO}

Atualmente o diabetes mellitus é considerado como uma das principais doenças crônicas que afetam o homem contemporâneo, acometendo populaçóes de países em todos os estágios de desenvolvimento. Sua importância nas últimas décadas vem crescendo em decorrência de vários fatores, tais como: maior taxa de urbanização, aumento da expectativa de vida, industrialização, sedentarismo, obesidade, dietas hipercalóricas e ricas em hidratos de carbono de absorçāo rápida, e também a maior sobrevida da pessoa diabética.

Trabalho apresentado na $3^{*}$ Conferència de Investigação em Enfermagem. Lisboa. Portugal, outubro 1991.

- Enfermeira e Mestre em Enfermagem - Doutoranda do Programa de Doutorado em Enfermagem Fundamental da EFRP. USP. Professor Assistente da Escola de Enfermagem de Ribeirào Preto da Universidade de Sáo Paulo. Brasil.

-. Enfermetra. Doutora e Livre-Docente em Enfermagem. Professor Titular e Vice-Diretora da Escola de Enfermagem de Ribeirào Preto da Unıversıdade de Sảo Paulo. Brasıl. 
As manifestaçōes crônicas são ainda na nossa realidade causas comuns de hospitalização e absenteísmo no trabalho. Sobressaem dentre elas, as doenças oculares, renais e vasculares que têm sido apontadas enquanto causas freqüentes de invalidez precoce.

Vários autores, ARDUINO (1973), MENDES (1975), MONDARDO (1982), JADZINSKY (1987), preconizam que para o sucesso da terapêutica, são primordiais o compromisso pessoal do diabético, visando uma adaptação e/ou ajustamento psicológico individual e familiar apropriado, e sobretudo um programa educacional e de apoio.

Observamos que as ações educativas têm sido realizadas com o objetivo principal de controle glicêmico, nāo levando em consideraçāo os aspectos psicológicos, sociais, culturais e de relacionamento. Desta forma, os níveis de aderência da pessoa diabética para o auto-cuidado têm se mostrado notoriamente baixos, evidenciando o fracasso da mesma em aderir a este comportamento.

Um motivo que explicaria este fracasso poderia estar nos programas que, em sua maioria, têm sua atençäo voltada para o conteúdo e quantidade de informaçōes necessárias para o auto-cuidado, segundo a percepção dos profissionais de saúde, não levando em consideraçāo as reais necessidades da pessoa diabética. Acresça-se, ainda, a falta de motivaçāo da pessoa diabética, bem como dos profissionais de saúde.

Esta problemática tem levado vários profissionais de saúde a desenvolver investigaçōes (veja, por exemplo, MENDES (1975), MONDARDO (1982), FRANCO (1988), que objetivam contribuir para elaboraçāo de programas em educaçăo, que subsidiem o conhecimento da pessoa diabética em relaçāo à sua doença e ao controle da mesma. Entretanto, vale ressaltar que tais programas nāo contemplam as questöes concernentes às crenças e motivaçōes para o controle da doença.

Além disso, há que se considerar que na Enfermagem tem sempre estado presente a preocupaçāo em educar a populaçāo no sentido de orientar, esclarecer, ensinar e informar os indivíduos, privilegiando os componentes cognitivos, que embora úteis, não têm produzido, na maioria das pessoas diabéticas, mudanças comportamentais. Considerando que o principal objetivo da educação em saúde da pessoa diabética é a mudança comportamental frente ao cuidado de saúde, visualizamos que os profissionais de enfermagem precisam contemplar os componentes efetivos quando da elaboração e execução de programas educativos.

A observação de LAGANA (1989) é a de que os enfermeiros reconhecem que a educação em saúde leva em conta componentes educacionais, sociológicos, antropológicos, de comunicação e de técnicas motivadoras, além de experièncias pessoais dos clientes, que englobam hábitos, crenças e valores, enfim, a multidimensionalidade 
da educação em saúde. Mesmo assim, os enfermeiros sentem dificuldades em transformar as propostas metodológicas e filosóficas em propostas operacionais.

Portanto, o cerne da moderna educaçāo em saúde reside na compreensão de que os comportamentos da pessoa podem determinar estilos de vida, de onde decorrem as doenças crônico-degenerativas, os acidentes e mortes violentas.

Assim, se voltarmos nossa atenção para a pessoa diabética, percebemos que a doença está intimamente relacionada ao estilo de vida da pessoa, assim como a obesidade, sedentarismo, dietas hipercalóricas e ricas em hidratos de carbono de absorção rápida, stress, dentre outras que exigem mudanças de comportamento para evitar o aparecimento da doença e/ou complicaçōes a médio e longo prazo.

Isto posto, significa dizer que comportamento e estilo de vida devem ser contemplados ao se planejar açóes educativas para a pessoa diabética, assim como no desenvolvimento de investigaçōes, uma vez que somente o conhecimento da doença e seus meios de controle não constituem base suficiente para as açóes de saúde. Essas tendências da educaçāo em saúde favorecem um repensar do agir do enfermeiro frente às práticas educativas.

O nosso trabalho com indivíduos portadores de diabetes mellitus levou-nos a refletir sobre o enfoque que LAGANA (1989) e REDECKER (1988) deram aos fatores pessoais e motivacionais, visando a aderência ao tratamento de indivíduos portadores de doenças crônico-degenerativas. Acresça-se que várias situações vivenciadas com pacientes diabéticos que envolviam a sua aderência ao tratamento permitiram-nos identificar as suas percepções e expectativas, sugerindo-nos a necessidade de um processo de ajuda mais individualizado, considerando os fatores pessoais e motivacionais. Dessa forma, entendemos que tal processo nāo pode se dar de forma padronizada para todos os individuos, sendo necessário redirecioná-lo visando as peculiaridades e/ou particularidades de cada um enquanto pessoa, com diferentes percepções, crenças, expectativas e valores.

Diante dessa preocupaçāo fomos buscar na literatura brasileira um instrumento que nos permitisse a análise de uma variável de personalidade chamada locus de controle.

ROTTER (1960) na década de 60 utilizou o termo locus de controle para designar o que, ou quem detém o controle, o foco de controle da determinação dos eventos, conforme percebido pelo indivíduo. $O$ constructo locus de controle é uma variável que busca explicar a percepção das pessoas em relação a fonte de controle dos acontecimentos: se esta for própria do sujeito, ela é interna; se for pertencente a algum elemento fora de si próprio, ela é externa. 
Assim, as pessoas tenderiam a perceber o exercício de controle sobre as ocorrências do mundo de maneira geral como, num extremo, dependente de suas próprias capacidades ou esforços ou, no outro extremo, dependentes de outras pessoas, de entidades, ou do acaso, sendo variáveis todas fora de seu próprio controle. Desse modo, os indivíduos posicionarse-iam em relaçäo ao locus de controle, através de um contínuo que variaria desde a internalidade extrema até a externalidade total.

Vários autores, a partir da conceituação e diferenciação estabelecida por ROTTER (1960), propōem a discriminaçāo de dois tipos de sujeitos externos: os externos autênticos, os externos defensivos ou outros poderosos.

Os sujeitos externos autênticos percebem a origem do controle como estando relacionados ao destino, azar, acaso e entidades sobrenaturais, sobre os quais nāo poderiam esperar exercer controle de forma alguma. Os sujeitos externos defensivos, ou externos outros poderosos, percebem o controle estando a cargo de outras pessoas, que um dia poderiam ainda ser controladas por elas.

\section{JUSTIFICATIVA E OBJETIVOS}

Conforme já explicitado, acreditamos que a percepçăo que a pessoa diabética tem em relaçāo à sua doença interfere na sua aderência ao tratamento e, certamente na adaptaçăo ao novo estilo de vida. Portanto, sentimos necessidade de identificar as crenças e atitudes da pessoa diabética em relação à saúde, como uma etapa precedente ao planejamento, organização e implementaçāo de programas educativos para diabéticos.

Para tal, se faz necessário inicialmente pesquisar a tendência do locus de controle desses individuos, através da utilizaçāo de um instrumento de medida.

A opçāo em utilizar o Instrumento de Medida de Locus de Controle à Saúde, proposto por BIAZIN (1987) e validado para a nossa cultura, encontra respaldo na literatura, pois ABDELLAH; LEVINE (1965), NEVES (1982), CASSIANI (1987) preconizam o desenvolvimento de estudos que utilizem estratégias de coleta de dados, previamente desenvolvidas, como também estudos de replicação que avaliem sua fidedignidade e validade.

Assim sendo, constituem objetivos desta pesquisa:

1) testar a fidedignidade do Instrumento de Medida de Locus de Controle à Saúde (IMLCS);

2) confrontar a distribuição das respostas aos diferentes itens do IMLCS para uma população de pacientes diabéticos, e 
3) verificar a predominância do Locus de Controle nos sujeitos estudados.

\section{METODOLOGIA}

Para o alcance dos objetivos propostos tornou-se necessária, inicialmente, efetuar a validaçāo aparente e de conteúdo do instrumento, sendo que para tal foram convidadas cinco juízas, enfermeiras que atuam em programas de atendimento à pessoa diabética.

Essas juízas foram orientadas individualmente, quanto aos objetivos da investigaçăo e ao instrumento a ser validado.

$O$ instrumento consta de dois conjuntos de dados. $O$ primeiro refere-se a folha de instrução e a folha de informação, em que sāo levantados alguns dados pessoa is e profissionais da populaçāo amostral. O segundo conjunto refere-se à escala, constando de dezenove afirmativas, sendo esses atributos referentes ao locus de controle para a saúde.

Assim, solicitamos a colaboração das juízas no sentido de validarem o referido instrumento quanto à clareza das sentenças, facilidade de leitura, compreensão e forma de apresentação, além de concordarem ou não quanto à retirada, acréscimo ou modificaçāo de itens e principalmente quanto aos atributos referentes ao locus de controle estarem pertinentes ou não a pessoa diabética.

A população amostral foi constituída por quarenta e oito indivíduos portadores de diabetes mellitus (Tipo 1 - insulinodependente e Tipo 2 - não insulinodependente), adultos, que soubessem ler e escrever e que nāo apresentassem comprometimentos da acuidade visual, permitindo-lhes ler.

Esses indivíduos săo atendidos nos serviços de a mbulatórios do Hospital das Clínicas da Faculdade de Medicina de Ribeirão Preto da Universidade de São Paulo (HCFMRP - USP) e Regional Especializado (ARE) do Sistema Unificado de Saúde - 50.

Para a coleta de dados contamos com a colaboração de quatro alunos do curso de graduação em enfermagem. Esses alunos foram previamente orientados quanto aos objetivos e finalidades do estudo, recebendo também treinamento quanto à aplicaçăo do instrumento de coleta de dados. Após esse treinamento, procuramos aplicar o instrumento, individualmente, em ambiente privativo, onde o paciente não tivesse qualquer tipo de interferencia, propiciando-lhe desse modo tranqüilidade na elaboração e emissảo de suas respostas.

Primeiramente, solicitamos ao paciente que realizasse a leitura da folha de instruçāo, colocando-nos à disposiçāo para esclarecer possíveis dúvidas. Após a aplicação da escala, foi efetuada a caracte- 
rizaçäo dos sujeitos e o teste de fidedignidade da escala, utilizando-se para tal a análise estatística e descritiva.

\section{ANÁLISE E DISCUSSĀo dOS RESULTADOS}

Para obtençāo das estimativas parciais dos coeficientes de fidedignidade, foi utilizado o Método do Cálculo pela Forma Alternativa subdividindo a escala em sub-escalas separando-se os itens referentes ao Locus de Controle Interno (LCI) e Locus de Controle Externo (LCE). Em outros termos, uma das sub-escalas foi constituída pelos itens dos números do LCI; uma segunda, por itens referentes ao LCE Acaso (LCE - A); a terceira por itens referentes ao LCE Outros Poderosos (LCE - OP) e a última pelos de LCE Misticismo (LCE - M).

Esses coeficientes de fidedignidade foram calculados através do Coeficiente de Correlaçāo Produto - Momento de Pearson (r).

4.1 Aplicação do Instrumento de Medida de Locus de Controle à Saúde frente a Pessoa Diabética

Validação Aparente e de Conteúdo

A partir das sugestōes das juízas, decorrentes da validação aparente e de conteúdo, fizemos algumas alteraçōes no instrumento, os quais passaremos a descrever.

Ao que se refere a folha de instrução nāo houve sugestōes de modificaçōes.

No primeiro conjunto do instrumento acrescentamos sugestōes de modificaçóes relacionadas aos itens números cinco e sete. Em relaçāo ao item número cinco, o qual se refere ao grau de instruçāo, foi acatada a seguinte sugestão: substituir a terminologia primário completo por primeiro grau completo e assim sucessivamente.

Após a a nálise dos investigadores quanto às sugestōes feitas pelas juízas em relação ao item sete, optamos pelo acréscimo dos seguintes itens: classificação do diabetes mellitus, segundo PUPO (1986); o tempo que a pessoa convive com a doença; se faz uso ou não de insulina; se o faz, há quanto tempo e as complicaçōes advindas de seu uso, bem como. a especificação dessas complicações, uma vez que esses dados poderiam ajudar na caracterização da população a mostral.

Quanto ao segundo conjunto, ou seja, a escala, houve sugestōes de modificação, nas palavras das sentenças de números: $1,2,7,10,13,18$.

Assim, na afirmação de número 1 , onde se lê a palavra estabelece, foi sugerida a palavra pratica ou têm; na sentença 2. onde se lê determina foi sugerida a substituiçảo por comanda: na sentença 
7 a palavra adequada por correta ou certa; na sentença 10 psíquico por da mente ou mental; na sentença 13, transtornos por problemas e finalmente na 18 acelera por aumenta.

Após a análise dessas sugestöes feitas pelas juízas, entendendo que as mesmas poderiam interferir no atributo locus de controle decidimos nāo acatá-las.

Apesar deste procedimento de validação aparente e de conteúdo ser considerado subjetivo (nâo de caráter estatístico), consideramos ter sido extremamente importante a sua realização, uma vez, que três juízas verbalizaram durante a validação do instrumento que "às vezes, ficamos tāo preocupadas em ensinar os pacientes como aplicar insulina; listar os alimentos que podem ser consumidos; falar da importância de realizar exercícios, que esquecemos essas outras dimensōes, ou seja, o conteúdo abordado nas afirmações". Logo, o trabalho serviu para reflexão dessas profissionais quanto à necessidade de levar em conta os objetivos a fetivos, além dos cognitivos em programas de educaçāo em diabetes.

\subsection{Caracterização dos sujeitos}

Entre os quarenta e oito sujeitos, a idade variou de 28 a 75 anos, sendo que a maior porcentagem, $87,50 \%$, encontra-se na faixa etária de 41 a 74 anos (Tabela 1).

TABELA 1. DISTRIBUIÇĀO DOS INDIVÍDUOS DIABÉTICOS ATENDIDOS NO ARESUDS-50 E HCFMRP - USP, SEGUNDO FAIXA ETÁRIA, EM RIBEIRĀO PRETO, JULHO 1990

\begin{tabular}{lrr}
\hline FAIXA ETÁRLA & N $^{2}$ & $?$ \\
\hline Até 28 anos & 2 & 4,17 \\
$29 \mid-40$ anos & 3 & 6,25 \\
$41 \mid-52$ anos & 10 & 20,83 \\
$53 \mid-64$ anos & 12 & 25,00 \\
$65 \mid-75$ anos & 20 & 41,67 \\
acima 75 anos & 1 & 2,08 \\
\hline Total & 48 & 100,00 \\
\hline
\end{tabular}

Esses achados vèm ao encontro de estudo realizado por FRANCO (1988), onde a prevalência do diabetes aumenta com o progredir da idade, especialmente após a quinta década de vida, em a mbos os sexos. 
Para os quarenta e oito sujeitos estudados, $60,42 \%$ pertencem ao sexo feminino e $39,58 \%$ ao sexo masculino.

Classicamente o diabetes é considerado mais prevalente no sexo feminino, porém existem controvérsias. ARDUINO (1973) atribui este fato ao maior número de mulheres acima de quarenta anos na população. ZAGURY et al (1987), no entanto, referem que o diabetes é uma doença de ocorrência mundial, independente do sexo, cor e raça. No estudo realizado por FRANCO (1988), embora a prevalência de diabetes mellitus seja maior no sexo feminino, essa diferença não foi estatisticamente significante.

Quanto ao estado civil $66,67 \%$ dos pacientes săo casados, $18,75 \%$ viúvos, $12,50 \%$ solteiros e $2,8 \%$ divorciados.

Acreditamos que estes dados devam ser considerados no planejamento de um programa de educação em diabetes, uma vez que a família desempenha um papel fundamental para a adaptação e/ou ajustamento psicológico do paciente em relação à sua doença.

No que se refere à religiäo, a grande maioria $79,17 \%$ dos pacientes estudados é católica (Tabela 2).

Tabela 2. Distribuiçāo dos indivíduos diabéticos atendidos no ARESUDS-50 E HCFMRP - USP, segundo religiāo, em Ribeirão Preto. julho 1990.

\begin{tabular}{lrr}
\hline RELIGLÄO & N & $\%$ \\
\hline Católica & 38 & 79,17 \\
Espírita & 2 & 4,17 \\
Crente de Deus e Amor & 1 & 2,08 \\
Protestante & 4 & 8,33 \\
Adventista & 1 & 2,08 \\
Testemunha de Jeová & 2 & 4,17 \\
\hline Total & 48 & 100,00 \\
\hline
\end{tabular}

BIAZIN (1987) coloca que na avaliaçāo do locus de controle o misticismo é importante, uma vez que é um comportamento freqüente na populaçāo brasileira, principalmente daquela da baixo nível sócioeconômico.

Quanto as ocupaçōes encontramos $17(35,41 \%)$ dos indivíduos diabéticos em pleno exercicio de suas atividades laborais (Tabela 3 ). 
TABELA 3. DISTRIBUIÇÃO DOS INDIVÍDUOS DIABÉTICOS ATENDIDOS NO ARESUDS-60 E HCFMRP - USP, SEGUNDO CATEGORIZAÇĀO DAS OCUPAÇŌES, RIBEIRĀO PRETO, JULHO 1990

\begin{tabular}{lrr}
\hline PROFISSAO & $\mathrm{N}^{2}$ & $\%$ \\
\hline Näo manual, não assaliariada & 1 & 2,08 \\
Não manual, assalariada & 3 & 6,25 \\
Manual, não assalariada & 9 & 18,75 \\
Manual, assalariada & 4 & 8,33 \\
Do lar & 20 & 41.67 \\
Aposentado & 9 & 18,75 \\
Sem informação & 2 & 4,17 \\
\hline Total & 48 & 100.00 \\
\hline
\end{tabular}

Observamos que $1(2,8 \%)$ dos individuos enquadra-se na categoria nāo manual, nảo assalariado (dentista); $3(6,25 \%)$ nāo manual, assalariado (professor de música, policial militar, corretor de seguros); 9 (18,75\%) manual, não assalariado (pintor de parede, soldador, costureira, pedreiro e servente); $4(8,32 \%)$ manual, assalariado (lavrador e doméstica); 20 $(41,67 \%)$ do lar; $9(18,75 \%)$ aposentado e $2(4,17 \%)$ não informou.

Em relação ao grau de instruçāo, encontramos que $52,09 \%$ tem $1^{\circ}$ grau incompleto e $33,33 \% 1^{\circ}$ grau completo, perfazendo um total de $85,42 \%$. Os restantes estão assim distribuídos: $2^{\circ}$ grau incompleto $4,17 \%$; $2^{\circ}$ grau completo $6,25 \% ; 3^{\circ}$ grau incompleto $2,08 \%$ e $3^{\circ}$ grau completo $2,08 \%$.

Em relação à renda mensal em termos de salário mínimo, $35,41 \%$ recebem de 1 a 2 salários mínimos por mès (Tabela 4 ).

TABELA 4. DISTRIBUIÇĀO DOS INDIVÍDUOS DIABÉTICOS ATENDIDOS NO ARESUDS-50 E HCFMRP - USP. SEGUNDO RENDA MENSAL. RIBEIRÃO PRETO, JULHO 1990.

\begin{tabular}{lrr}
\hline RENDA MENSAL & $N^{2}$ & $\%$ \\
\hline Dependente & 5 & 10,42 \\
1 a 2 S.M. & 17 & 35,41 \\
2 a 3 S.M. & 2 & 4,17 \\
3 a 4 S.M. & 9 & 18,75 \\
4 a 5 S.M. & 5 & 10,41 \\
5 a 6 S.M. & 3 & 6,25 \\
6 A 7 S.M. & 2 & 4,17 \\
Acima de 7 S.M. & 5 & 10,42 \\
\hline Total & 48 & 100.00 \\
\hline
\end{tabular}


Observamos nas Tabelas 3 e 4 a predominância da ocupaçāo do lar e a renda mensal de 1 a 2 salários mínimos. Esses dados são concordantes com obtidos por MENDES (1975), VEIGA (1979), MONDARDO (1982).

VEIGA (1979) afirma que existe associação significante à nível de 5\% entre o grau de instruçāo e sinais e sintomas de diabetes como fraqueza, emagrecimento, acidose diabética, prurido em órgāo genitais e lesāo de extremidades. Relata ainda essa associação entre categoria sócio-econômica, a hipertensão arterial e o emagrecimento.

MENDES (1975) diz que a condição sócio-econômica e o nivel cultural sāo fatores que nāo podem ser esquecidos na assistência aos pacientes diabéticos.

Apesar de essas duas variáveis serem de ordem social, o profissional de saúde nāo pode perdê-las de vista no planejamento e execução de programas educacionais e assistenciais. Acreditamos que estas variáveis possam constituir fatores preponderantes para a aderência do paciente diabético ao tratamento.

Em relação ao diabetes mellitus, encontramos $27 \%$ do tipo 1 . insulinodependente e $73 \%$ do Tipo 2 - Nāo Insulinodependente (Tabe(a 5).

TABELA 5. DISTRIBUIÇĀO DOS INDIVÍDUOS DIABÉTICOS ATENDIDOS NO ARESUDS-50 E HCFMRP - USP, SEGUNDO O TIPO DE DIABETES, RIBEIRĀO PRETO, JULHO 1990.

TIPOS DE DIABETES

Tipo 1 - Insulinodependente

tipo 2 - Nāo Insulinodependente

Total
$\mathrm{N}^{2}$

13

35

73

100,00

Esses achados coincidem com resultados encontrados por ARDUÍNO (1973), BURISCH; BRADLEY (1983), PUPO (1986), FRANCO (1988), que mostraram que a grande maioria dos pacientes com diabetes mellitus sāo classificados como tipo 2, ou seja, não insulinodependente.

Entre os pacientes do estudo, a duraçāo da doença variou entre 1 mês e 16 anos (Tabela 6). 
TABELA 6. DISTRIBUIÇĀO DO TIPO DE DIABETES (DMID)* (DMNID)**, SEGUNDO TEMPO DE DIAGNÓSTICO DA ENFERMIDADE, RIBEIRÃO PRETO, JULHO DE 1990 (TABELA 10).

TEMPO DE DOENÇA

DMID

DMNID

\begin{tabular}{lcccr} 
& $\mathrm{N}^{2}$ & $\%$ & $\mathrm{~N}^{2}$ & $\%$ \\
\hline 1 mes $-\mid 5$ anos & 7 & 53,95 & 20 & 57,14 \\
$6-\mid 10$ anos & 1 & 7,69 & 10 & 28,57 \\
$11-\mid 15$ anos & 3 & 23,08 & 2 & 5,71 \\
$16-\mid 20$ anos & 2 & 15,38 & 3 & 8,58 \\
\hline Total & 13 & 100,00 & 35 & 100,00 \\
\hline
\end{tabular}

* DMID - Diabetes Melitus Insulinodependente

- DMNID - Diabetes Melitus Nāo Insulinodependente

Nesta tabela observamos que, o tempo de aparecimento da doença variou de 1 mês a 5 anos em $7(53,95 \%)$ dos indivíduos portadores de DMID e $20(57,14 \%)$ dos DMNID.

\subsection{Fidedignidade da Escala}

A análise descritiva dos itens foi feita segundo o aparecimento dos mesmos referentes aos atributos de locus de controle. Assim os itens números $1,2,5,7,10,11$ e 18 referem-se a sub-escala LCI; os de números 4,9 e 17 à sub-escala LCE-A, os de números $3,6,8,14$, 15 e 19 a sub-escala LCE-PO e os de números 12,13 e 16 à sub-escala LCE-M. Verificadas as porcentagens de sujeitos que responderam às alternativas de cada item, os dados foram categorizados em dois grupos.

O primeiro foi composto pelas alternativas concordo plenamente, concordo muito, concordo pouco, e o segundo pelas alternativas discordo pouco, discordo muito, discordo plenamente. Esse agrupamento foi feito na tentativa de verificarmos a tendência do sujeito a estar favorável ou desfavorável em relação a afirmação contida no item analisado.

A seguir apresentaremos os itens a nalisados de cada sub-escala. 
Síntese dos Resultados da Sub-escala 1: do total de 7 (100\%) itens dessa sub-escala, todos foram respondidos pelos sujeitos de maneira FAVORÁVEL.

Síntese dos Resultados da Sub-escala 2: do total de 3 (100\%) itens dessa sub-escala, todos foram respondidos pelos sujeitos de maneira FAVORÁVEL.

Síntese dos Resultados da Sub-escala 3: do total de 6 (100\%) itens dessa sub-escala, todos foram respondidos pelos sujeitos de maneira FAVORÁVEL.

Síntese dos Resultados da Sub-escala 4: do total de 3 (100\%) itens dessa sub-escala; todos foram respondidos pelos sujeitos de maneira FAVORÁVEL.

\subsection{Análise Estatistica}

A aplicação do IMLCS teve como finalidade, através da análise dos dados colhidos em todos os itens da escala, determinar o coeficiente de fidedignidade, sendo que optamos pelo Método do Cálculo pela Forma Alternativa, através do coeficiente de Correlação do Produto Momento de Pearson (r).

Segundo PARADINE; RIVETT (1974) com uma única aplicaçāo de um teste é possivel chegar a uma medida de fidedignidade. Para tal, a escala foi subdividida primeiramente em duas subescalas, separando-se os itens do locus de controle interno e locus de controle externo. Em seguida a escala foi subdividida em 4 sub-escalas, denominadas de Locus de Controle Interno (LCI); Locus de Controle Externo-Acaso (LCE-A); Locus de Controle Externo-Outros Poderosos (LCE-OP); Locus de Controle Externo - Misticismo (LCE-M).

Quanto aos escores para as respostas dadas pelos sujeitos às alternativas dos itens eles foram estabelecidos da seguinte forma: a alternativa A obteve escore 6 ; a B escore 5 ; a C escore 4; a D escore 3; a $\mathrm{E}$ escore 2 e a $\mathrm{F}$ escore 1.

Foram calculados a somatória dos escores obtidos nas respostas dos sujeitos as alternativas dos itens referentes à cada sub-escala, as médias e os desvios padrão a fim de verificarmos se apresentava correlaçào entre as duas variáveis.

Segundo PARADINE; RIVETT (1974) o coeficiente de correlaçāo indica uma tendência de qualquer uma das variáveis aumentar quanto a outra também aumenta.

Apresentamos a seguir a matriz de intercorrelação do IMLCS, elaborada a partir do estudo de BIAZIN (1987). 
TABELA 7 - MATRIZ DE INTERCORRELAÇĀO DO IMLCS DERIVADA A PARTIR DOS DADOS DE BLAZIN (1987).

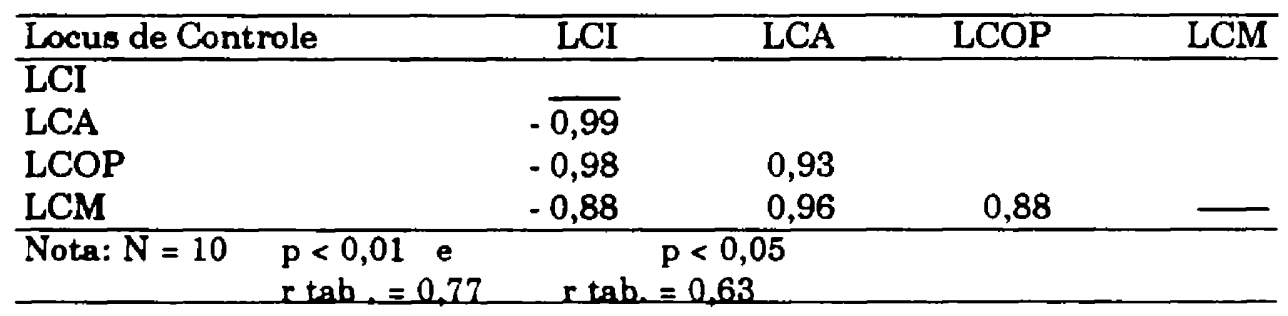

O Instrumento de Medida de Locus de Controle à Saúde (IMCLS), aplicado a uma amostra de 10 pacientes paraplégicos sob regime de autocateterismo intermitente, nāo estéril, apresentou os resultados expressos na Tabela 7 . Todas as escalas apresentaram correlaçāo significativa entre si para p 0,01 e p 0,05 . Acreditamos que esses resultados se devam ao pequeno número de pacientes $\mathrm{da}$ amostra $(n=10)$ em relação ao número de sub-escalas.

\section{TABELA - 8 - MATRIZ DE CORRELAÇĀO DO IMLCS DO ESTUDO REALIZADO POR NÓS.}

\begin{tabular}{|c|c|c|c|c|}
\hline & $\overline{\mathrm{LCI}}$ & LCA & LCOP & LCM \\
\hline & \multicolumn{4}{|c|}{ LCI } \\
\hline LCA & $\overline{0,17}$ & & & \\
\hline LCOP & 0,56 & $\overline{0,54}$ & & \\
\hline LCM & 0,31 & 0,53 & $\overline{0,51}$ & \\
\hline $\begin{array}{rl}\text { Nota: } N=48 & p< \\
& r t a\end{array}$ & & 0,05 & & \\
\hline
\end{tabular}

O Instrumento de Medida de Locus de Controle à Saúde (IMCLS), aplicado à uma amostra de 48 indivíduos diabéticos, apresentou os resultados expressos na Tabela 8 . A escala Locus de Controle Interno não apresenta correlação significativa com a escala Locus de Controle - Acaso ( $p$ 0,05). No entanto observamos correlação significativa das demais escalas entre si.

A correlação média para sub-escala variou de .31 a .56 , e todas foram significativas ou ao nivel de significancia de 0,01 ou 0,05 . Aparentemente estas correlaçóes são mais indicativas e mais próximas do esperado do que aquelas obtidas por BIAZIN (1987).

Analisando a correlaçāo significativa entre LCI E LCE - Outros Poderosos, encontramos, segundo WALLSTON; DE VELLIS (1978) que uma pessoa com forte crença no locus de controle externo, por poder de outros, tem grande confiança no agente terapèutico e, teoricamente, estaria mais predisposta a submeter-se a um dado procedimento. 
TABELA 9 - DISTRIBUIÇÃO DAS RESPOSTAS DOS SUJEITOS QUANTO AO LOCUS DE CONTROLE.

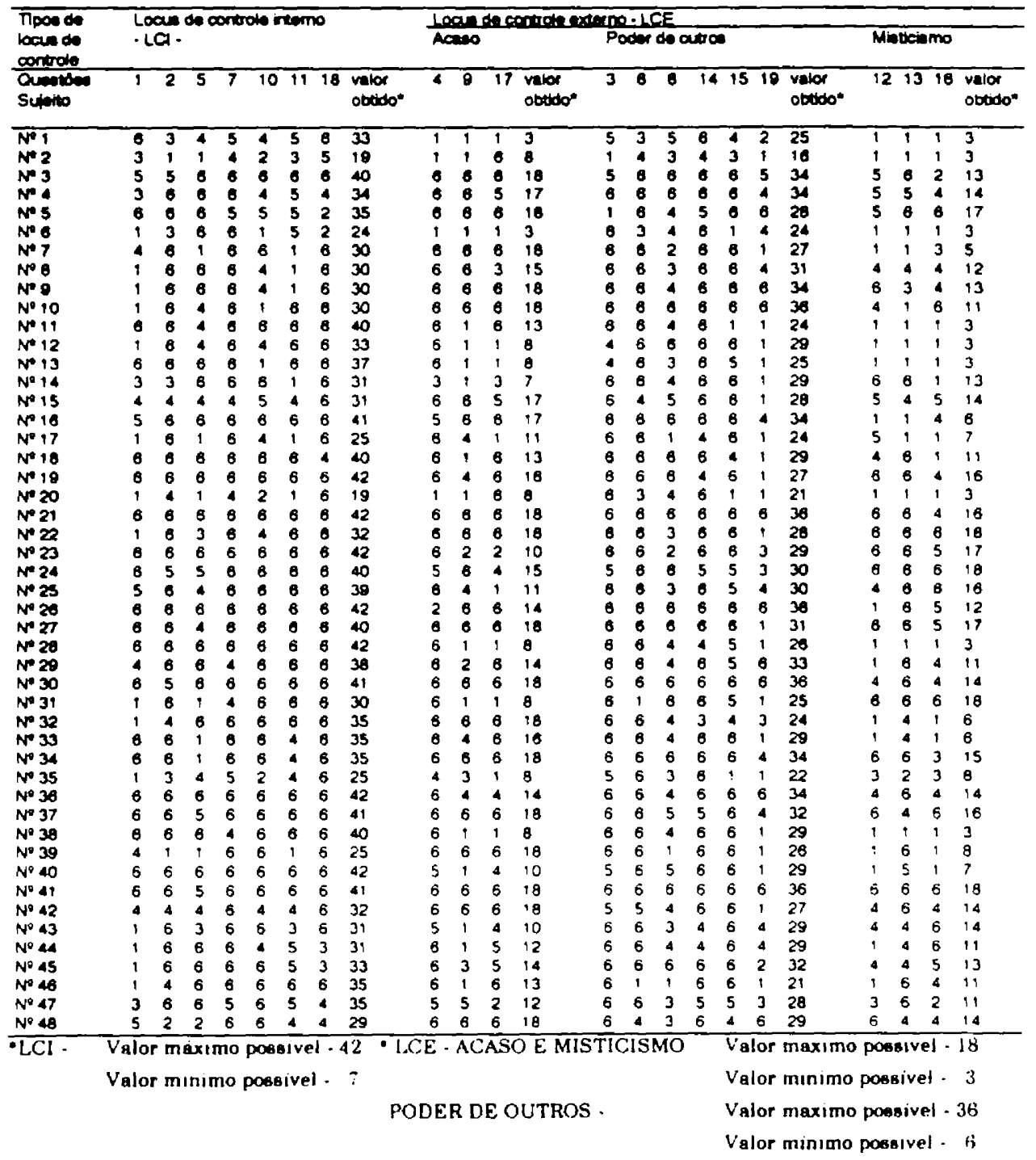

Quanto à predominância dos sujeitos em relaçāo ao locus de controle, observamos que em sua grande maioria $(93,8 \%)$, os sujeitos sāo predominantemente externos e que somente $3(6,2 \%)$ são internos, no que se refere ao seu locus de controle (veja Tabela 9).

LOWERY; DUCETTE (1976) encontraram que os pacientes diabéticos com locus de controle predominantemente internos buscam mais informaçōes sobre a doença que os externos, e conseqüentemente 
apresentam maior aderência ao tratamento. STANTON (1988) acrescenta que os indivíduos com o locus de controle interno aparentemente desejam assumir mais responsabilidade para decisão quanto ao seu auto-cuidado.

A inter-relaçāo entre o sucesso dos indivíduos paraplégicos no desempenho de auto-cateterismo e o locus de controle interno foi relatado por BIAZIN (1987).

Com base na teoria da aprendizagem social de ROTTER, não há razão para esperar que os resultados obtidos nos instrumentos, por si só, expliquem muito da variação obtida em comportamentos de saúde. Somente terāo um papel significante na explicação do comportamento, quando em interaçāo com outros fatores que contribuem na determinaçāo de crenças no locus de controle à saúde. No caso de pacientes diabéticos em especial, essa interação poderá vir associada à competência para o auto-cuidado com a pele, dieta, administração de insulina, entre outros.

Consideramos que a determinação do locus de controle para os pacientes diabéticos é importante; no entanto, a utilizaçāo de instrumentos para avaliá-lo nảo poderá vir desvinculada da fundamentação teórica e empírica do locus de controle à saúde.

WALLSTON; DE VELLIS (1978) afirmam que, como indicador específico, os instrumentos de medida do locus de controle à saúde nos dāo uma idéia da expectativa generalizada da crença em saúde do indivíduo.

Nossos resultados nāo nos permitem concluir a interrelação entre locus de controle externo e o fracasso na aderência de pacientes diabéticos ao tratamento. A presente investigação permitiu-nos, no entanto, identificar o locus de controle desses pacientes diabéticos, para posterior avaliação de suas potencialidades em termos de aderència ao tratamento.

A experiência tem nos mostrado que há uma grande dificuldade destes pacientes em aderir ao tratamento. Isto nos leva acreditar que além dos fatores discutidos no presente estudo, a motivação e as crenças em saúde podem constituir fatores preponderantes para tal adesão.

Considerando que a grande maioria dos pacientes aqui estudada evidenciou o locus de controle externo, necessários se fazem outros estudos, que correlacionem a identificação do locus de controle com outros fatores, a fim de se poder contribuir para a elaboraçăo de programas em educaçảo em diabetes que realmente possibilitem levar este paciente a aderir ao regime de auto-cuidado, favorecendo a sua adaptação e ou ajustamento.

Nesta última década a educação do paciente tem recebido muita ênfase; as razōes para isto sāo muitas e incluem grande demanda de conhecimentos pelo paciente, pressão legal (principalmente nos Estados Unidos), promoção para o auto-cuidado, medidas preventivas. 
altas hospitalares precoces, maior incidência de doenças crônicas, e a crença por parte dos enfermeiros de que a educaçāo do paciente favorece prontidāo, e conseqüentemente, saúde e bem-estar.

A educação em saúde tem sempre feito parte do papel da enfermeira e quando nós criamos oportunidade de aprendizagem sobre uma doença crônica, tal como o diabetes, a enfermeira tem oportunidade de dar uma contribuiçäo positiva para que o indivíduo no futuro possa manter o controle sobre sua doença.

\section{CONCLUSÕES}

Este estudo permitiu-nos concluir que:

1) em relação ao teste de fidedignidade através da validação concorrente, podemos considerar que a escala está validada para a amostra populacional de pacientes diabéticos.

2) em relação à distribuição das respostas aos diferentes itens do IMLCS, temos que o grau de instruçāo interfere na favorabilidade ou desfavorabilidade das respostas dos sujeitos para cada item.

3) em relação ao locus de controle, concluímos que $93,8 \%$ dos sujeitos têm o seu locus de controle predominantemente externo.

\section{RECOMENDAÇÄO}

Que os enfermeiros ao elaborarem programas de saúde para pessoas diabéticas, devam incorporar os objetivos afetivos às açóes educativas, uma vez que os sujeitos estudados mostraram uma predominância no locus de controle externo.

ZANETTI, M. L.; MENDES, I. A. C. The tendency of locus of control in diabetic patients.

Rev. Esc. Ent. USP., v. 27, n. 2. p. 246-62, aug. 1993.

The tendency of locus of control in diabetic patients is a theme approached by the nurse as an educator. The objectives of this study was to test reliability of the "Instrumento de Medida de Locus de Controle is Saude (IMLCS)" (Instrument of Measurement of Locus of Control for Health); to confront the distribution of responses to different items of the "IMLCS" by a group of diabetic patients; and to verify the predominance of locus of control for health in the subjects studied. To reach these objectives the "IMLCS" was applied. The data showed that there was a prevalence of subjects with a locus of external control, that the different items were answered in a favorable manner by the subjects and that the scale was valid for the population of diabetic patients. We believe that these results shou the need for rethinking the role of the nurse in the education of diabetic patients.

UNITERMS: Locus of control, diabetes 


\section{REFERÊNCIAS BIBLIOGRÁFICAS}

ABDELLAH, F.G.; LEVINE, E. Better patient care through research. New York, The Macmillan, 1965.

ARDUINO, P. Diabetes Mellitus o suns complicaçós. Rio de Janeiro, Guanabara Koogan, 1973.

BIAZIN, D.T. Locu de controle e desempenho no auto-cateterismo: estudo em paciente paraplégico. Ribeirảo Preto, 1987, 194p. Dissertação (Mestrado) - Escola de Enfermagem de Ribeiráo Preto., Universidade de São Paulo.

BURISH, G.T.; BRADLEY, L.A. Coping with chronic disease. New York, Academic Press, 1983.

CASSIANI, S. de B. A coleta de dados nas pesquisan em enfermagem: estratégias, validade e confiabilidade. Ribeiráo Preto, 1987, 156p. Dissertaçáo (Meatrado)-Escola de Enfermagem de Ribeirão Preto, Universidade de Sáo Paulo.

FRANCO, L.T. Estudo sobre a prevelència do diabetes mellitus na populaçào de 30 a 69 anos de idade do município de Sào Paulo. 1988. 54p. Tese 1 Livre-Docència)-Escola Paulista de Medicina.

JADZINSKY, M. Diabetes Mellitus, porque educar? IN: ENCONTRO NACIONAL DE EDUCAÇÄO EM DIABETES, 1, Vitória, 1987. Anais. Vitória, 1987. p.11.4.

LAGANÁ, M.T.C. Educaçáo para saúde ou saúde para educação? Bol.Inf.ENC., v.2, n.6, p.2, 1989.

LOWERY, J.B.; DUCETTE, P.J. Diseaso-related learning and disease control in diabetics as al function of locus of control. Nurs.Res., v. 25, n.5, p. 358-62, 1976.

MENDES, I.A.C. Observaçào da administraçào de insulina em pacientes diabéticos no domićllio. Rio de Janeiro, 1975. 79p. Dissertaçáo (Mestrado)-Escola de Enfermagem Ana Neri, Universidade Federal do Rio de Janeiro.

MONDARDO, S.T. Estudo das açòes de enfermagem praticadas no ambula tório do Hoopital de Clínicas de Porto Alegre a pacientes diabéticos. Porto Alegre, 1982. 49p. Dissertaçáo (Mestrado)-Univeroidade Federal do Rio Grande do Sul.

NEVES, E.P. Palestra proferida durante a Semana de Pesquisa da UFSC. In: GONÇALVES, L.H.T. Desenvolvimento de um instrumento de pesquisa: medidas de atitude dos adultos em relaçāo ao velho. Santa Catarina, 1982. 81 p. Tese (Livre-Docencia)-Universidade Federal de Sta. Catarina.

PARADINE, C.G.; RIVETT, B.H.P. Métodos estatísticos para tecnologistas. São Paulo, Poligono/EDUSP, 1974

PUPO, A. de A. Diabetes 87: fatos e perspectivas. Rev.Assoc.Med.Bras., v.32, n.11/12, p.185-6, 1986.

PUPO, A. de A. Diagnóstico e classificação do diabetes. Rev.Assoc.Med.Bras., v.32. n.11/12, p.194-6, 1986.

REDEKER, N.S. Health beliefs and adherence in chronic-iliness. Image, v 20, nm.1, p.31-5, 1988 .

ROTTER, J.B. Some implications of a social learning theory for the prediction of goal directed behavior from testing procedures. Psychol Rev., v.67, p.301-16. 1960.

STANTON, M.P. Nurse/Patients interaction in the teaching/earning environment. Todays OR Nurse, v. 10, n.5, p. 10-4, 1988.

VEIGA, D.A. Estudo da frequencia de problemas de saúde em clientes com Diabete Melito, num hospital de Porto Alegre. Porto Alegre, 1979. 92p. Disser. taçāo (Mestrado)-Universidade Federal do Rio Grande do Sul.

WALLSTON, A.K. DE VELLIS, R. Development of the multidimensional health: locus of control scales (MHLC). Health Educ.Monogr., v.6, p. 160-70, 1978.

ZAGURY. L. et al. Diabetes sem medo. 4.ed. Rio de Janeiro. Rocca, 1987. 